\title{
Exploring the link between teachers' educational belief profiles and different types of computer use in the classroom
}

\author{
Jo Tondeur*, Ruben Hermans, Johan van Braak, Martin Valcke \\ Department of Educational Studies, Ghent University, Henri Dunantlaan 2, B9000 Ghent, Belgium
}

Available online 8 April 2008

\begin{abstract}
The purpose of the study reported in this article was to analyse the relationship between teachers' educational beliefs and their typical approach to computer use in the classroom. In this context, the question arises whether particular profiles of teachers can be distinguished based on their beliefs about good education. A survey of 574 elementary school teachers was conducted that focused both on teachers' traditional or constructivist beliefs about education and on different types of computer use: 'computers as an information tool', 'computers as a learning tool' and 'basic computers skills'. Cluster analysis resulted in four distinct teacher profiles, reflecting relatively homogeneous scale scores, based on varying levels of traditional and constructivist beliefs teachers hold about education. Overall results indicate that teachers with relatively strong constructivist beliefs who also have strong traditional beliefs report a higher frequency of computer use. In addition, results point at a specific relationship between teachers' belief profiles and how computers are used in the classroom. Implications for the role of educational beliefs in supporting teachers to integrate ICT in the classroom are discussed.

(C) 2008 Elsevier Ltd. All rights reserved.
\end{abstract}

Keywords: Teachers; Computer use; Educational beliefs; Primary education

\footnotetext{
* Corresponding author. Tel.: +32926486 74; fax: +3292648688.

E-mail address: Jo.Tondeur@UGent.be (J. Tondeur).
} 


\section{Introduction}

The integration of information and communication technology (ICT) in education has challenged researchers for almost 20 years. In this respect, many studies have focused on measuring the impact of attitudes toward computers (Albirini, 2006; Shapka \& Ferrari, 2003), computer experience (Bovée, Voogt, \& Meelissen, 2007; van Braak, 2001) and computer training (Galanouli, Murphy, \& Gardner, 2004; Tan, Hu, Wong, \& Wettasinghe, 2003). However, results of an earlier study (van Braak, Tondeur, \& Valcke, 2004) indicate that the overall impact of these variables on the use of computers in the classroom remains rather low.

Clearly, the issue cannot be restricted to merely technology-related factors. The integration of educational computer use in professional competencies of teachers implies a more complex approach. What determines whether and how a teacher uses computers in the classroom? There is a growing consensus that the adoption of educational innovations can only be explained when also educational beliefs of teachers are taken into account (Becker, 2001; Ertmer, Addison, Lane, Ross, \& Woods, 1999; Higgins \& Moseley, 2001). According to Pajares (1992), teachers interpret innovations according to their personal beliefs. In other words, teachers accept more easily innovations that are in accordance with their personal conceptions of teaching and learning. ICT integration in education is therefore unlikely to succeed unless we understand teachers' personal educational beliefs and their relationship with teaching practices (Niederhauser \& Stoddart, 2001).

There is a growing body of published research that underpins the hypothesis that teachers' beliefs affect classroom practices (Fang, 1996; Haney, Lumpe, Czerniak, \& Egan, 2002). But, research about the relation between teacher beliefs and ICT integration is still scarce. However, recent studies (Becker, 2001; Ertmer, 2005; Higgins \& Moseley, 2001; Sugar, Crawley, \& Fine, 2004) reveal that teachers' educational beliefs tend to be associated with their use of computers in the classroom. Becker (2001), for instance, revealed that constructivist beliefs foster computer use in education. But the latter findings are not helpful to explain the nature of educational computer use. Little is know about the relationship between educational beliefs and specific types of computer use in the classroom.

This study aims to determine which teacher beliefs are connected to different types of computer use. Therefore the study first researches whether profiles can be developed that reflect a typical set of beliefs adopted by teachers. A next step is to examine how different teacher profiles are related to different types of computer use. Before presenting the results of the empirical study, we first examine how computer use has been defined in recent educational computing research. In a next section, we describe the concept of teachers' educational beliefs and how they are likely to influence the use of computers in the classroom.

\section{Background}

\subsection{Computer use in the classroom}

Within the context of educational computer use, a range of definitions, classifications and typologies can be found. Published studies reflect particular views on computer use in a learning environment. Many researchers have measured computer use by reporting the time teachers and pupils spend using computers or the amount of technology used in the classroom (e.g., Mathews \& Guarino, 2000; O’Dwyer, Russell, \& Bebell, 2004). 
In other studies, the focus is rather on specific software applications. The questionnaire designed by Kent and Facer (2004), for example, reflects a range of computer activities in order to compare pupils' home and school use of computers. Although these studies are valuable, they hardly help to clarify the integrated educational use of the software. Becker (2000) presented both software and an instructional application approach. His survey asked teachers to name the software that is considered to be most valuable in their teaching. Similarly, Waite (2004) reported teachers' responses about the aims and uses of computers in primary schools.

Only a limited number of studies centre on the instructional objectives pursued by integrating computer use. A clear example is the Second Information Technology in Education Study, (SITES, Module 2 by Kozma, 2003). Based on qualitative and quantitative methods, clusters of pedagogical practices building on computer use were identified. Also, Ainley, Banks, and Fleming (2002) identified categories of educational computer use such as "computers as information resource tools", "computers as authoring tools" and "computers as knowledge construction tools". In the same way, Baylor and Ritchie (2002) differentiate between types of educational computer use, including "the use of computers for collaboration" or "the use of computers for higher order skills".

Although each of the available studies enriches the picture of educational computer use, a comprehensive instrument that integrates types of computer use in the context of primary education is yet not available. Therefore, a prior empirical study was set up to identify a typology of actual computer use in primary education (Tondeur, van Braak, \& Valcke, 2007). The results suggest a three-factor structure, labelled as "basic computer skills" (to develop pupils technical computer skills), "the use of computers as an information tool" (to research and process information) and "the use of computers as a learning tool" (to practice knowledge and skills) and demonstrate the need of examining computer use from a multi-faceted, rather than a singular, perspective (O'Dwyer et al., 2004; Tondeur et al., 2007). The scales to identify these three types of computer use are described in the research method section. In the present study we relate these types of computer use to teachers' educational belief profiles and investigate possible differences. Different types of computer use could refer to different beliefs about learning and instruction.

\subsection{Educational beliefs}

"Beliefs" can be described as psychological understandings, premises or propositions felt to be true (Richardson, 2003). The complete set of someone's beliefs on the physical and social world and the self is clustered in a belief system (Rokeach, 1976). Beliefs and belief systems serve as personal guides in helping individuals to define and understand the world and themselves (Pajares, 1992). They allow us "to proceed as if the world makes perfectly good sense” (Cunningham, Schreiber, \& Moss, 2005, 179).

Teachers' educational beliefs are understandings, premises or propositions about education (Denessen, 2000), established by multitudinous experiences (Nespor, 1987; Pajares, 1992). Teachers' beliefs are considered as relatively stable and act as a filter through which new knowledge and experiences are screened for meaning (Campbell, Kyriakides, Muijs, \& Robinson, 2004; Kagan, 1992; Nespor, 1987; Pajares, 1992). In contrast to integrated models of teaching, beliefs consist of an eclectic mix of rule of thumb, generalisations, opinions, values and expectations (Lowyck, 1994) that underlie teachers' planning, decision making and behaviour in the classroom (Fang, 1996; Kagan, 1992; Nespor, 1987; Pajares, 1992). 
Scholars in the field of educational research have been developing and validating a variety of instruments for measuring teachers' educational beliefs (e.g., Hermans, van Braak, \& Van Keer, 2008; Kerlinger \& Kaya, 1959a, 1959b; Woolley, Benjamin, \& Woolley, 2004). In the past, a conceptual shift in research on the dimensionality of the belief construct has taken place, and researchers have turned their attention toward a multidimensional approach to structure the belief system. Fifty years ago, for example, Kerlinger and Kaya (1959a, 1959b) criticized the bipolar distinction between teacher-centred "traditionalistic" and more "progressive" or student-centred educational beliefs. Their study provided support for the hypothesis that teachers hold both "traditionalistic" and "progressive" educational beliefs. Recently, Woolley et al. (2004) developed the "Teachers Beliefs Survey" (TBS). In their instrument, the dimension "traditional teaching" mainly focuses on traditional approaches to the curriculum and assessment. The second dimension, "constructivist teaching", embraces student-centred approaches to teaching and learning. Considering the fact that teachers are expected to adopt concurrent educational beliefs, the question is put forward whether specific belief profiles can be found in teachers, based on the extent to which they adopt traditional and constructivist teaching beliefs.

\subsection{The link between educational beliefs and computer use in the classroom}

Even though the conditions for successful ICT integration finally appear to be in place such as access to infrastructure, increased computer skills and sufficient computer training - the implementation of educational computer use has not yet reached a critical level (Scrimshaw, 2004; van Braak et al., 2004). This suggests, as stated above, that additional barriers specifically related to teachers' educational beliefs, might be at work (Ertmer, 2005). In the research literature it is acknowledged that teachers' beliefs tend to be associated with their specific use of ICT in the classroom (e.g., Becker, 2001; Ertmer, 2005; Windschitl \& Sahl, 2002). Several studies explain this by hypothesizing that teachers who use computers do so because their conceptions of using ICT fit into their existing teaching beliefs or belief system (Higgins \& Moseley, 2001; Sugar et al., 2004). If the teacher perceives that the computer addresses important instructions and learning needs, the perceived value will be higher (Niederhauser \& Stoddart, 2001).

There is growing evidence that teachers, adopting constructivist beliefs, are highly active computer users (Becker, 2001; Niederhauser \& Stoddart, 2001). It appears that computers serve as a valuable instructional tool in classrooms in which teachers hold personal beliefs aligned with constructivist pedagogy. Since educational authorities present ICT especially as a tool for enacting student-centred curricula (Hawkridge, 1990), teachers adopting strong traditionalist educational beliefs are less likely to use computers in their classroom practice (Ertmer, 2005).

Given the differences in beliefs, it is expected that teachers' approaches to use ICT will also differ. It is therefore necessary to understand how computers are being used in the context of teaching and learning (O’Dwyer et al., 2004; Tondeur et al., 2007). A computer does not embody one single pedagogical orientation; it offers a spectrum of approaches to teaching and learning. According to Niederhauser and Stoddart (2001), teachers select applications of computers in line with their selection of other curricular variables and processes (e.g., instructional strategies) that fit into their existing educational beliefs. Only recently researchers have studied educational computer use in relation to teacher belief systems (Windschitl \& Sahl, 2002). The research evidence available shows that low-level computer 
use tend to be associated with teacher-centred practices, while high-level use tend to be associated with student-centred, or constructivist practices (Ertmer, 2005). Constructivist teachers are also more likely to use computers in more challenging ways (Becker, 2001).

\subsection{General aim of the present study}

This study builds on the idea that educational beliefs affect decisions about classroom practices, including the issue of computer use. While previous researchers have documented the link between teachers' educational beliefs and computer use, this paper studies the relationship between profiles in teacher beliefs and different types of computer use. The first step in this study was to delineate teacher profiles based on the extent to which they possess traditional and constructivist teaching beliefs. The second step was to examine how different teacher profiles relate to different types of computer use, more specifically (1) "basic computer skills", (2) "the use of computers as an information tool" and (3) "the use of computers as a learning tool".

\section{Research method}

\subsection{Sample}

Data collection was restricted to teachers in primary schools in Flanders, the Dutchspeaking part of Belgium. A stratified sample of 70 schools was involved in the study. Stratification variables were related to the type of educational network and the degree of urbanisation (rural/urban). Fifty-seven school principals were willing to participate in the study, reflecting an $81.4 \%$ response rate at school level. At least one teacher at each grade level completed a questionnaire, resulting in data from at least six teachers per school. The sample comprised 574 teachers, of which $81.5 \%$ were female. Teacher age varied from 22 to 64 years, with an average age of 37 .

\subsection{Instruments}

A questionnaire was developed in order to gather information from teachers about their educational beliefs and about their use of computers in the classroom. The questionnaire consisted of two parts: (1) teachers' educational beliefs and (2) different types of computer use in the classroom.

\subsubsection{Measuring teachers' educational beliefs}

In this study, teachers' beliefs about education were measured through two scales, developed by Woolley et al. (2004). Their "teacher beliefs survey" for primary teachers contains two sub-dimensions: "traditional teaching" (TT) and "constructivist teaching" (CT). The TT scale contains items such as, "I teach subjects separately, although I am aware of the overlap of content and skills" or "For assessment purposes, I am interested in what students can do independently". In addition to the traditional dimension, examples of the CT scale are "I involve students in evaluating their own work and setting their own goals" and "I make it a priority in my classroom to give students time to work together when I am not directing them". Respondents were asked to rate each statement on a five-point scale: $0=$ "totally disagree", $1=$ "disagree", $2=$ "neither agree nor 
disagree", $3=$ "agree" and $4=$ "totally agree". Internal consistency was measured with Cronbach's $\alpha$ : TT scale $(\alpha=.74)$ and CT scale $(\alpha=.68)$. The results also suggest that there is a positive association between both beliefs scales $(r=0.22, p<.01)$.

\subsubsection{Measuring different types of computer use}

To verify whether profiles in teacher beliefs are related to different types of computer use in the classroom, an additional instrument (Tondeur et al., 2007) was included in the questionnaire. This instrument synthesises the actual types of computer use in Flemish primary education. "Basic computer skills" ( 3 items) identifies the use of computers as a (separate) school subject to teach pupils technical computer skills, such as "I teach the pupils to make good use of the keyboard and mouse" and "I teach pupils learning basics of operating systems used at school". The second and third categories represent educational uses of computers not restricted to its use as a school subject. "Computers as an information tool" (5 items) encompasses such aspects as "The pupils use the computer to select and retrieve information" and "The pupils use the computer as a demonstration tool". Emphasis is on the interaction between pupils and the subject-domain content: researching and processing information and communication. Finally, the category "Computers as learning tools" (4 items) includes items such as "The pupils use the computer to practice knowledge or skills" and "The pupils use the computer to elaborate learning content". The respondents were asked to indicate, on a five-point scale, the extent to which they use the computer for various tasks: $0=$ "never", $1=$ "every term", $2=$ "monthly", $3=$ "weekly" and $4=$ "daily". Control of the psychometric quality of the research instrument reveals a high internal consistency level for "basic computer skills" $(\alpha=.81)$, "computers as an information tool" $(\alpha=.83)$ and "computers as learning tools" $(\alpha=.77)$. Table 1 shows the correlations between the three sum scales.

The results suggest that there is a reasonable positive association between "Basic Skills" and both "Information tool" and "Learning tool". In educational practice, it is often less easy to differentiate in a straightforward way between the three types of computer use (Tondeur et al., 2007). For example, the distinction between basic computer skills and educational computer use can be marred by the fact that technical use of computers involves nevertheless some knowledge construction. In the present study, analysis results suggest that when teachers stress the use of computers as information and learning tool, they are also likely to stress the development of basic computer skills.

\subsection{Data analysis}

First, a cluster analysis was performed to identify profiles in the teacher educational beliefs (k-mains clustering procedure). Cluster analysis helps to group a number of individuals into clusters so that individuals within a cluster are more similar to each other than

Table 1

Pearson product-moment correlation coefficients among the three types of computer use

\begin{tabular}{llc}
\hline & Information tool & Learning tool \\
\hline Basic computer skills & $.48^{\mathrm{a}}$ & $.41^{\mathrm{a}}$ \\
Learning tool & $.30^{\mathrm{a}}$ & \\
\hline
\end{tabular}

\footnotetext{
${ }^{\text {a }}$ Correlation is significant at the .001 level.
} 


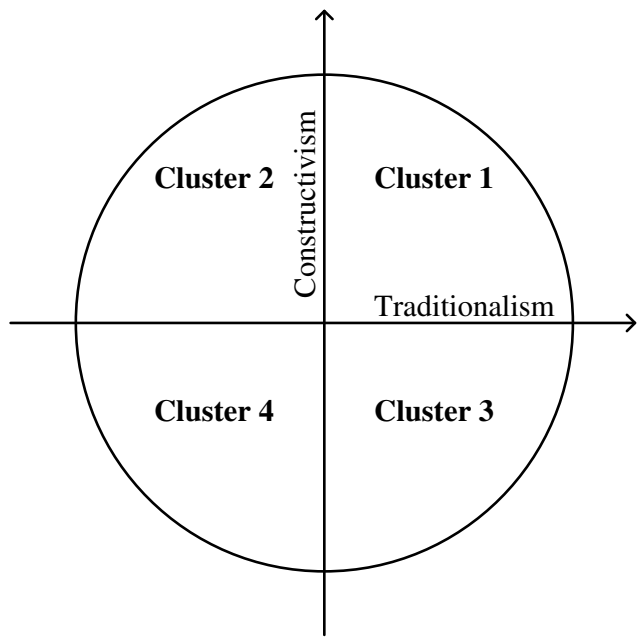

Fig. 1. Four cluster solution based on the TT Scale and CT Scale.

those from other clusters (Aldenderfer \& Blashfield, 1984); this is also called multivariate similarity (Gore, 2000). Scores on the two educational belief scales "traditional teaching" and "constructivist teaching" (Woolley et al., 2004) were used to develop the profiles. The results thus obtained allow us to better understand how teachers possess both traditional and constructivist teaching beliefs. Since cluster analysis is also an interpretative quantitative procedure, there is no single solution to the analysis, and the choice for a specific number of final clusters is subjective. A four-solution analysis was pursued in this study, building on the scores on the two scales (Fig. 1).

Second, the differential impact of the four profiles in teacher beliefs on types of educational computer use was studied by computing one-way ANOVA's. Scheffe post-hoc tests were computed to study specific contrasts between teacher profiles when significant differences were found.

\section{Results}

\subsection{Four profiles in teachers' educational beliefs}

The first analysis examined whether teacher profiles can be defined by classifying them according to traditional and constructivist educational beliefs. Based on cluster analysis, the respondents were distributed among four clusters as follows: 180 were classified as cluster 1 (34\% of the 523 respondents), 140 were grouped in cluster $2(27 \%), 171$ teachers belonged to cluster $3(33 \%)$, and 32 could be found in cluster $4(6 \%)$. Fig. 2 presents the mean scores of the two classification measures of each cluster. To facilitate data analysis, sum scores were calculated for the two educational belief scales (minimum 0 - maximum $100)$.

The differences between the mean scores of the clusters were statistically significant for both scale scores, with the exception of the difference between cluster 3 and 4 on the CT scale score. Teachers in cluster 1 reflect a profile with relatively high scores on both the TT Scale and CT Scale. In contrast to this "constructivist and traditional profile" (C\&TP), are 


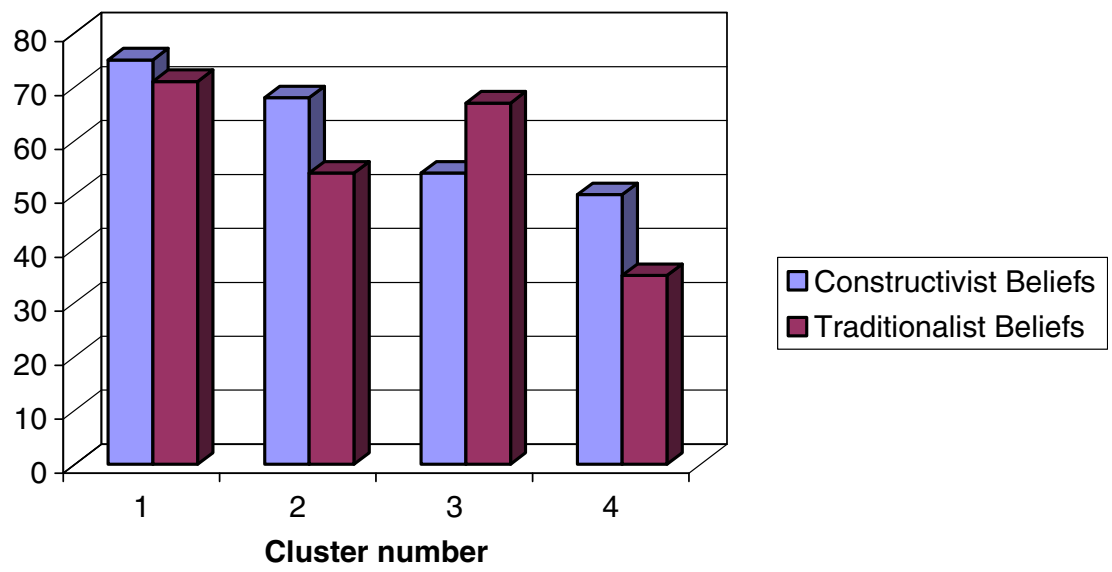

Fig. 2. Mean scores of the clusters (profiles) on the TT Scale and CT Scale.

teachers in cluster 4 . Cluster 4 brings together teachers with a profile that reflects low scores on both the CT and the TT Scale. Teachers in this cluster are stated to reflect an "undefined profile" (UP). Teachers in cluster 2 had relatively high mean scores on the CT Scale but relatively low scores on the TT Scale. Therefore the profile of teachers in this cluster is labelled as "constructivist profile" (CP). In contrast, teachers in cluster 3 are defined as reflecting a "traditional profile" (TP).

\subsection{Linking teacher profiles and types of computer use}

In the next step, we included Multivariate analysis of variance (MANOVA) to test the differences in computer use statistically. The belief profiles were entered as independent variables to compare the three types of computer use in each cluster. Based on the Wilks' lambda criterion, the multivariate test shows a significant cluster effect $(F(3,507)=5.284$; $p<0.001)$. The corresponding ANOVA's also reveal significant cluster effects: "Computer Skills" $(F(3,507)=3.676 ; p=0.012)$, “information tool" $(F(3,510)=13.535 ; p=0.000)$ and "learning tool" $(F(3,510)=13.535 ; p=0.000)$. Fig. 3 shows the cluster mean for three types of computer use in the classroom.

In accordance with the findings mentioned above, teacher profiles represented in clusters 1 and 2 (C\&TP and CP) with relatively stronger constructivist beliefs, report a higher frequency of computer use on the three different scales. Post-hoc analyses (Sheffe criterion) were conducted to verify whether different teacher profiles are related to different types of computer use in the classroom. Significant differences are summarised in Table 2.

The results highlight a significant difference between cluster 1 (C\&TP) and 3 (TP) in the categories "computer skills" and use of "computers as information tool". Teachers in cluster 1 (C\&TP) scored significantly higher on both types of computer use. The post-hoc tests also revealed a significant relationship between cluster 2 (CP) and cluster 3 (TP). Teachers in cluster $2(\mathrm{CP})$ rated significantly higher in the use of "computers as information tool". Finally, teachers belonging to cluster 4 (UP) reported on average a significantly lower score on the use of "computers as a learning tool" than teachers in cluster 1 (C\&TP). Remarkably, compared to teachers in cluster 1 (C\&TP), teachers cluster 3 (TP) had a sig- 


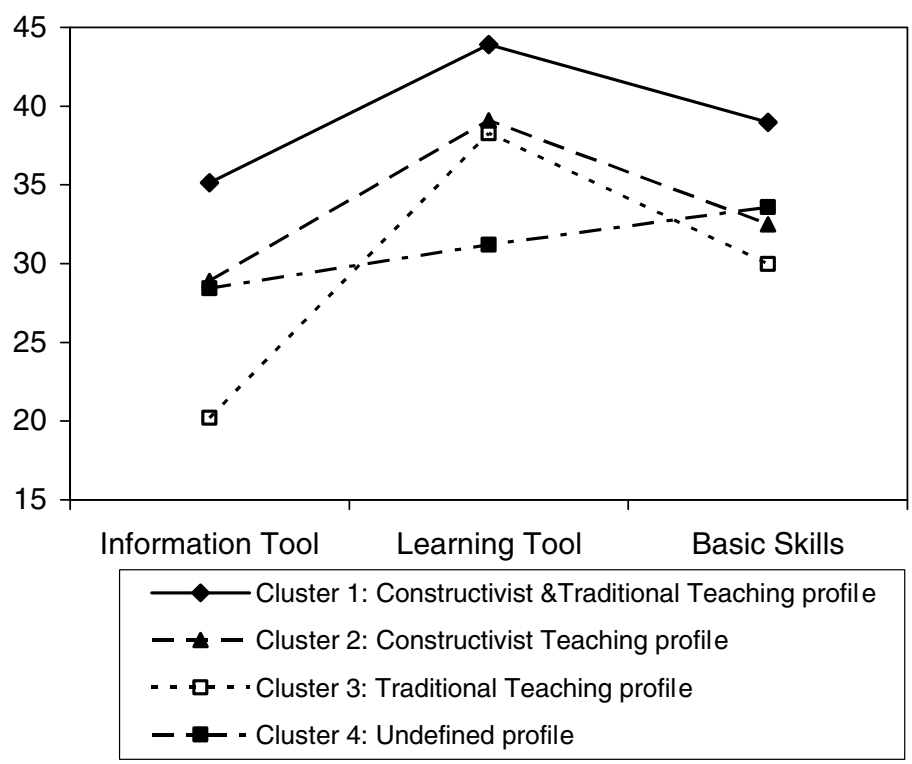

Fig. 3. Mean scores of the clusters on three types of computer use.

Table 2

Overview of significant difference between the clusters for each type of ICT use

\begin{tabular}{|c|c|c|c|c|}
\hline \multirow[t]{2}{*}{ Type of ICT use } & \multicolumn{4}{|c|}{ Multiple comparisons } \\
\hline & Clusters/profile & Mean difference & Standard error & $p$ \\
\hline Computer skills & $1-3$ & 8.99 & 2.79 & 0.016 \\
\hline \multirow[t]{2}{*}{ Information tool } & $1-3$ & 14.92 & 2.35 & 0.000 \\
\hline & $2-3$ & 8.69 & 2.50 & 0.007 \\
\hline Learning tool & $1-4$ & 12.72 & 4.41 & 0.041 \\
\hline
\end{tabular}

nificantly lower mean score on both "computer skills" and "use of computers as information tool" but not on "use of computer as learning tool".

No significant effect was found between cluster 1 (C\&TP) and 2 (CP). These teachers reflect relatively high scores on "constructivist teaching". However, teachers in cluster 1 (C\&TP) report higher scores on the three types of computer use. Furthermore, no significant differences were found between teachers in cluster 3 (TP) and cluster 4 (UP). Although the differences are not statistically significant, it is worth noting that the mean scores of teachers with an undefined profile were higher in comparison with traditionalist profile teachers, with the exception of the scores on the "learning tool" scale.

\section{Discussion}

Results of the present study indicate a consistent relationship between teacher profiles, based on their educational beliefs, and the frequency of class use of computers: a teacher profile with relatively high constructivist beliefs tends to show a high frequency of educational computer use. This finding is in accordance with earlier research about the role of 
educational beliefs in relation to ICT integration in classroom practice (Becker, 2001; Granger, Morbey, Lotherington, Owston, \& Wideman, 2002). As stated earlier, it could be argued that computers serve as a valuable instructional tool in classrooms in which teachers hold personal beliefs aligned with constructivist pedagogy (Becker, 2000). Interestingly, a teacher profile with relatively high constructivist beliefs and also high traditionalist beliefs leads to the most frequent adoption of all types of computer uses. One possible explanation is that, since teachers use computers in ways that are consistent with their personal beliefs, a broader spectrum of educational beliefs might result in a more diverse use of ICT. This result provided support for the hypothesis that teachers hold both traditionalist and constructivist educational beliefs. As stated earlier, researchers (e.g., Kerlinger \& Kaya, 1959a, 1959b) criticized the bipolar distinction between teacher-centred "traditionalistic" and more "progressive" or student-centred educational beliefs and have turned their attention toward a multidimensional approach to structure the belief system.

Furthermore, teacher belief profiles tend to be associated with different types of computer use. This result confirms the importance of examining different types of computer use (O'Dwyer et al., 2004; Tondeur et al., 2007). Teachers with a traditional teaching profile for example are less likely to use "computers as an information tool" where the emphasis lies on the autonomous interaction between the pupil and the subject-domain content. Pupils are given more degrees of freedom when the computer is used to research and processing information when compared to the two other types of computer use. It could be suggested that the use of "computers as an information tool" is a high-level use of computers, associated with more student-centred, or constructivist practices. In addition, teachers with a traditional teaching profile are much more likely to use "computers as a learning tool" as compared to using "computers as an information tool". For this group of primary teachers, drill-and-practice activities on the computer are more common. It can be suggested that teachers are likely to adopt practices with computers that are in line with their beliefs about teaching.

The results indicate that the use of ICT is mediated by teachers' beliefs about teaching and learning. Considering our result, what is the role of teachers' educational beliefs in supporting them to integrate ICT in the classroom? Since professional development is a crucial factor in the process of ICT integration in education, it might be useful to design professional development schemes that take into account educational beliefs (Antonietti \& Giorgetti, 2006; Higgins \& Moseley, 2001). How to facilitate and support this in a pre- or in-service training approach is less clear, especially for staff developers that are familiar with the development of technical ICT skills. In this respect, staff developers might consider introducing ICT to accomplish that which is already valued (Ertmer, 2005). According to Zhao and Cziko (2001), the further a new teaching practice is from the existing practice, the less likely it will be implemented successfully. Once a computer application is integrated, the emphasis can switch to its potential for achieving additional aims, including those that are supported by broader or different educational beliefs (Ertmer, 2005).

The belief-action relationship must be seen as bi-directional: beliefs lead to actions, which, in turn, lead to the creation of new, reconstructed or reaffirmed beliefs (Haney et al., 2002). Teachers' practices and belief profiles are continually shaped by their ongoing experience as teachers (Becker \& Ravitz, 1999). Past studies indicate that, in conjunction with the use of ICT over time, teachers often change their classroom practice and adopt more student-centred, constructivist beliefs (e.g., Becker \& Ravitz, 1999; Honey \& Moeller, 1990). However, these studies have not offered clear explanations for why some teach- 
ers transform their beliefs or change their belief profile. Windschitl and Sahl (2002) stipulate that the conditions of ubiquitous ICT alone, do not automatically initiate teachers' shift towards constructivist beliefs. It can be argued that, to include the use of computers, teachers must have models of how computers work in the classroom and must be supported to reflect on their own role in the learning process. Observing successful ICT integration might increase teachers' perceived need for change as well as assure them that the required changes are not impossible (Zhao \& Cziko, 2001). They must be personally convinced of its benefits and see the utility of using a particular technology (Lam, 2000). This might explain why in-service approaches that build on good practices are appreciated and valued by teachers.

Policymakers still tend to operate as if educational change is a unidirectional process (Niederhauser \& Stoddart, 2001). They assume teachers will accept and implement innovations such as ICT integration mandated from top down. This is often not the case (Tondeur, van Braak, \& Valcke, 2007). In fact, if teachers feel pressured to change their educational beliefs in order to integrate ICT, they are more likely to resist adopting ICT (Zhao \& Cziko, 2001). In this context, the school level plays a key role. It is in the workplace that the model should be situated, opportunities for learning provided and positive reinforcement and support offered. Problems can arise if teachers, working within the same project, have different conceptions about the role of ICT (Antonietti \& Giorgetti, 2006). It is recommended that school administrators work closely with teachers to address their beliefs and concerns about ICT integration and provide an influential level of personal support and resources (Sugar et al., 2004). In this respect, preparing an ICT curriculum at school level can be a crucial step towards the practical integration of ICT in the classroom through the setting of shared educational goals and the means to realise them. The development of an ICT school policy gives stakeholders the opportunity to reflect about their educational beliefs in relation to their use of ICT.

Given the current emphasis on ICT integration in education and the importance of teacher beliefs, future research should focus in depth on the belief/teaching relationship. The next step is to adopt qualitative approaches that build on classroom observation and to study whether teachers adopt types of computer applications that are consistent with their educational beliefs. Another issue which requires further study is the influence of contextual school factors on teachers' capacity to apply their beliefs in daily classroom practice. Local school policies are in this context of importance. The latter requires more advanced statistical techniques (i.e., multilevel analysis). The advantage of multilevel modeling techniques is that it takes different levels within a hierarchy of nested variables into account (Gorard, 2003). The observations of individual teachers are not completely independent of what teachers share in their school setting (Hox, 1995). Finally, research is needed to verify the relative impact of professional development initiatives in influencing teachers' belief profiles.

\section{Conclusions}

This research has focused on how profiles of teachers' educational beliefs affect the integration of ICT in education. Overall results suggest that teachers with a profile that represents both strong constructivist and strong traditionalist beliefs are more likely to adopt educational computer use. It seems that, to fully utilise the wide range of educational possibilities offered by ICT, a broad profile of educational beliefs is required. Furthermore, 
teachers' belief profiles tend to be associated with different types of computer use. This relationship might gain a greater appreciation for why teachers don't make wider use of ICT. As a consequence, an understanding of teacher beliefs is an important factor in supporting further ICT integration in education.

\section{References}

Ainley, J., Banks, D., \& Fleming, M. (2002). The influences of IT: Perspectives from five Australian schools. Journal of Computer Assisted Learning, 18, 395-404.

Albirini, A. (2006). Teachers' attitudes toward information and communication technologies: The case of Syrian EFL teachers. Computers and Education, 47, 373-398.

Aldenderfer, M. S., \& Blashfield, R. K. (1984). Cluster analysis. Beverly Hills, CA: Sage Press.

Antonietti, A., \& Giorgetti, M. (2006). Teachers' beliefs about learning from multimedia. Computers in Human Behavior, 22, 267-282.

Baylor, L. A., \& Ritchie, D. (2002). What factors facilitate teacher skill, teacher moral, and perceived student learning in technology-using classroom? Computers and Education, 39, 395-414.

Becker, H. J. (2000). Findings from the teaching, learning and computing survey: Is Larry Cuban right? In Paper presented at the school technology leadership conference of the council of chief state school officers, Washington, DC.

Becker, H. J. (2001). How are teachers using computers in instruction? In Paper presented at the annual meeting of the American educational researchers association, Seattle. http://crito.gsm.uci.edu/tlc.

Becker, H. J., \& Ravitz, J. (1999). The influence of computer and internet use on teachers' pedagogical practices and perceptions. Journal of Research on Computing in Education, 31, 356-384.

Bovée, C., Voogt, J., \& Meelissen, M. (2007). Computer attitudes of primary and secondary students in South Africa. Computers in Human Behavior, 23, 1762-1776.

Campbell, J., Kyriakides, L., Muijs, D., \& Robinson, W. (2004). Assessing teacher effectiveness: Developing a differentiated model. London: RoutledgeFalmer.

Cunningham, D. J., Schreiber, J. B., \& Moss, C. M. (2005). Belief, doubt and reason: C.S. Peirce on education. Educational Philosophy and Theory, 37, 177-189.

Denessen, E. (2000). Opvattingen over onderwijs (Beliefs about education). Apeldoorn, The Netherlands: Garant.

Ertmer, P. A., Addison, P., Lane, M., Ross, E., \& Woods, D. (1999). Examining teachers' beliefs about the role of technology in the elementary classroom. Journal of Research on Computing in Education, 32, 54-72.

Ertmer, P. A. (2005). Teacher pedagogical beliefs: The final frontier in our quest for technology integration? Educational Development Research and Development, 53, 25-39.

Fang, Z. H. (1996). A review of research on teacher beliefs and practices. Educational Research, 38, 47-65.

Galanouli, D., Murphy, C., \& Gardner, J. (2004). Teachers' perceptions of the effectiveness of ICT-competence training. Computers and Education, 43, 63-79.

Gorard, S. (2003). What is multilevel modelling for? British Journal of Educational Studies, 51, 46-63.

Gore, P. A. (2000). Cluster analysis. In H. E. A. Tinsley \& S. D. Brown (Eds.), Handbook of applied multivariate statistics and mathematical modeling (pp. 297-321). San Diego, CA: Academic Press.

Granger, C. A., Morbey, M. L., Lotherington, H., Owston, R. D., \& Wideman, H. H. (2002). Factors contributing to teachers, successful implementation of IT. Journal of Computer Assisted Learning, 18, $448-480$.

Haney, J. J., Lumpe, A. T., Czerniak, C. M., \& Egan, V. (2002). From beliefs to actions: The beliefs and actions of teachers implementing change. Journal of Science Teacher Education, 13, 171-187.

Hawkridge, D. (1990). Who needs computers in school, and why? Computers and Education, 15, 1-6.

Hermans, R., van Braak, J., \& Van Keer, H. (2008). Development of the beliefs about primary education scale: Distinguishing a developmental and transmissive dimension. Teaching and Teacher Education, 24, 127-139.

Higgins, S., \& Moseley, D. (2001). Teachers' thinking about information and communications technology and learning: Beliefs and outcomes. Teacher Development, 5, 191-210.

Honey, M., \& Moeller, B. (1990). Teacher's beliefs and technology integration: Different values, different understandings. CTE Technical Report Issue No. 6. http://www.edc.org/CCT/ccthome/reports/tr6.html.

Hox, J. J. (1995). Applied multilevel analysis. Amsterdam, The Netherlands: TT-Publikaties.

Kagan, D. M. (1992). Implications of research on teacher belief. Educational Psychologist, 27, 65-90. 
Kent, N., \& Facer, K. (2004). Different worlds. A comparison of young people's home and school ICT use. Journal of Computer Assisted Learning, 20, 440-455.

Kerlinger, F. N., \& Kaya, E. (1959a). The construction and factor analytic validation of scales to measure attitudes toward education. Educational and Psychological Measurement, 19, 13-29.

Kerlinger, F. N., \& Kaya, E. (1959b). The predictive validity of scales constructed to measure attitudes toward education. Educational and Psychological Measurement, 19, 305-317.

Kozma, R. (Ed.). (2003). Technology, innovation and educational change: A global perspective. Eugene, OR: Information Society for Technology in Education [ISTE] Publications.

Lam, Y. (2000). Technophilia vs. technophobia: A preliminary look at why second-language teachers do or do not use technology in their classrooms. Canadian Modern Language Review, 56, 390-420.

Lowyck, J. (1994). Teaching effectiveness: An overview of studies. Tijdschrift voor Onderwijsresearch, 19, 17-25.

Mathews, J. G., \& Guarino, A. J. (2000). Predicting teacher computer use: A path analysis. International Journal of Instructional Media, 27, 385-392.

Nespor, J. (1987). The role of beliefs in the practice of teaching. Journal of Curriculum Studies, 19, $317-328$.

Niederhauser, D. S., \& Stoddart, T. (2001). Teachers' instructional perspectives and use of educational software. Teaching and Teacher Education, 17, 15-31.

O’Dwyer, L. M., Russell, M., \& Bebell, D. J. (2004). Identifying teacher, school and district characteristics associated with elementary teachers' use of technology: A multilevel perspective. Education Policy Analysis Archives, 12, 1-33.

Pajares, M. F. (1992). Teachers beliefs and educational research: Cleaning up a messy construct. Review of Educational Research, 62, 307-332.

Richardson, V. (2003). Pre-service teachers' beliefs. In J. Raths \& A. C. McAninch (Eds.), Teacher beliefs and classroom performance: The impact of teacher education (pp. 1-22). Greenwich, CT: Information Age Publishing.

Rokeach, M. (1976). Beliefs, attitudes and values. A theory of organization and change. San Francisco, CA: JosseyBass.

Scrimshaw, P. (2004). Enabling teachers to make successful use of ICT. http://becta.org.uk.

Shapka, J. D., \& Ferrari, M. (2003). Computer-related attitudes and actions of teacher candidates. Computers in Human Behaviour, 19, 319-334.

Sugar, W., Crawley, F., \& Fine, B. (2004). Examining teachers' decisions to adopt new technology. Educational Technology and Society, 7, 201-213.

Tan, S. C., Hu, C., Wong, S. K., \& Wettasinghe, C. M. (2003). Teacher training on technology-enhanced instruction - A holistic approach. Educational Technology and Society, 6, 96-104.

Tondeur, J., van Braak, J., \& Valcke, M. (2007). Primary school curricula and the use of ICT in education. Two worlds apart? British Journal of Educational Technology, 38, 962-975.

Tondeur, J., van Braak, J., \& Valcke, M. (2007). Towards a typology of computer use in primary education. Journal of Computer Assisted Learning, 23, 197-206.

van Braak, J. (2001). Factors influencing the use of computer mediated communication by teachers in secondary schools. Computers and Education, 36, 41-57.

van Braak, J., Tondeur, J., \& Valcke, M. (2004). Explaining different types of computer use among primary school teachers. European Journal of Psychology of Education, 19, 407-422.

Waite, S. (2004). Tools for the job: A report of two surveys of information and communications technology training and use for literacy in primary schools in the West of England. Journal of Computer Assisted Learning, 20, 11-20.

Windschitl, M., \& Sahl, K. (2002). Tracing teachers' use of technology in a laptop computer school: The interplay of teacher beliefs, social dynamics, and institutional culture. American Educational Research Journal, 39, $165-205$.

Woolley, S. L., Benjamin, W-J. J., \& Woolley, A. W. (2004). Construct validity of a self-report measure of teacher beliefs related to constructivist and traditional approaches to teaching and learning. Educational and Psychological Measurement, 64, 319-331.

Zhao, Y., \& Cziko, G. A. (2001). Teacher adoption of technology: A perceptual control theory perspective. Journal of Technology and Teacher Education, 9, 5-30. 